\title{
A Study on Construction of Brand Image for Cultural Tourism Based on Visual Grammar --- Taking the Brand Image of "Mystery" of Xiangxi as an Example
}

\author{
Ying Liu \\ College of International Education, Jishou University, China
}

\begin{abstract}
With the deep integration development of culture and tourism, cultural tourism brand has become an important factor of core competitiveness. As the brand of cultural tourism of Xiangxi Tujia and Miao Autonomous Prefecture (hereafter referred to as Xiangxi), "Mystery" represents the core value of Xiangxi's culture and tourism. The publicity video of Mysterious Xiangxi becomes the important carrier of the "Mystery" brand, playing a vital role in the transmission of brand image. This paper illustrates and analyzes the constructing features of brand image of "Mystery" from dimensions of representation meaning, interactive meaning and composition meaning respectively based on visual grammar, and puts forward some suggestions on it combining with four factors of cultural brand image design.
\end{abstract}

Keywords: Visual grammar; Mystery; Xiangxi; brand image

\section{Introduction}

With the deep integration development of culture and tourism, tourists' expectations for tourism services and specialties are constantly becoming higher and higher, so effective tourism brands are crucial factors in the competition of culture and tourism industry. Tourism industry is a strategic pillar industry in Xiangxi. It sets "Mystery" as its cultural tourism brand, which just fits its cultural essence. Compared to other tourism orientation, the biggest competitive advantage is not just its rugged mountains and green waters, but also the ethnic culture, folk custom and mysterious culture. (Li, 2011) Besides clear position of the brand image, its effective communication is more important. The publicity video of Mysterious Xiangxi plays a vital role in spreading the brand of "Mystery" and attracting domestic and foreign tourists.

According to the previous study, most domestic researches focus on its communication strategies or marketing strategies. There are few studies on analyzing the brand image of ethic culture tourism from the perspective of social semiotics. How does Mysterious Xiangxi construct and spread brand of "Mystery"? This study takes the official publicity video of Xiangxi, Mysterious Xiangxi as an example, analyzes the constructing features of brand image of "Mystery" from dimensions of representation meaning, interactive meaning and composition meaning respectively based on visual grammar and puts forward some suggestions to improve the effectiveness of transmission of tourism brand and enhance the communication competence of local ethical culture.

\section{Visual grammar}

Visual grammar is to study the way how the people, places and things are depicted in the images, their relations with the viewers, and the way they are integrated into a meaningful whole. Kress and van Leeuwen's visual grammar provides the methodologies to interpret the meaning of image systematically. Its basic principle is to take Michael Halliday' social semiotic approach to analyze other semiotic resources like image, gesture, music and so on, to study the meaning "potential" and structure. These semiotic resources are viewed as inter-related meaning-making systems, which are used to construe social practice. Following Hodge and Kress (1988:1), everything in society and culture "can be seen as a form of communication". Halliday' model with its three functions sets a starting point for description of image because it works well as a source for thinking about all modes of representation." (Kress \& van Leeuwen, 2006 [1996]) In recent years, scholars at home and abroad have conducted extensive research on the multimodal discourse analysis. The social semiotic approach to multimodal analysis construes the meaning of multiple semiotic resources such as language, gesture, proximity, gaze, music and so forth in order to establish the framework of multimodal symbolic semantics. According to the development and research of multimodal discourse analysis, it is not only a theoretical 
research framework but also an important approach of discourse analysis.

\section{Interpreting the brand image of "Mystery" from visual grammar}

The data selected in this study is the official publicity video named Mysterious Xiangxi released by local government. It includes the introduction and four short episodes, "Green Xiangxi”, "Cultural Xiangxi”, "Open Xiangxi" and "Harmonious Xiangxi". The brand image of "Mystery" is constructed through the semiotic resources like images, words, music, sound, color, time and so on.

\begin{tabular}{|c|c|c|c|c|c|c|}
\hline Semio- & & image & words & music & sound & colour \\
\hline $0^{\prime} \quad 45^{\prime \prime}$ & $\begin{array}{l}\text { Introduce- } \\
\text { tion }\end{array}$ & $\sqrt{ }$ & $\sqrt{ }$ & $\sqrt{ }$ & $\checkmark$ & $\checkmark$ \\
\hline $\begin{array}{l}0^{\prime} \quad 48^{\prime \prime} \\
2^{\prime} \quad 32^{\prime \prime}\end{array}$ & $\begin{array}{l}\text { "Green } \\
\text { Xiangxi" }\end{array}$ & $\sqrt{ }$ & $\sqrt{ }$ & $\sqrt{ }$ & $\sqrt{ }$ & $\sqrt{ }$ \\
\hline $\begin{array}{l}2^{\prime} 33^{\prime \prime} \\
4^{\prime} \frac{45^{\prime \prime}}{}\end{array}$ & $\begin{array}{l}\text { "Cultural } \\
\text { Xiangxi” }\end{array}$ & $\sqrt{ }$ & $\sqrt{ }$ & $\sqrt{ }$ & $\sqrt{ }$ & $\sqrt{ }$ \\
\hline $\begin{array}{l}4^{\prime} \quad 46^{\prime \prime} \\
7^{\prime} \quad 07^{\prime \prime}\end{array}$ & $\begin{array}{l}\text { "Open } \\
\text { Xiangxi” }\end{array}$ & $\sqrt{ }$ & $\sqrt{ }$ & $\sqrt{ }$ & V & V \\
\hline $\begin{array}{l}7^{\prime} 08^{\prime \prime} \\
8^{\prime} \frac{-35^{\prime \prime}}{}\end{array}$ & $\begin{array}{l}\text { "Harmo- } \\
\text { nious } \\
\text { Xiangxi" } \\
\text { and ending }\end{array}$ & $\sqrt{ }$ & $\sqrt{ }$ & $\sqrt{ }$ & 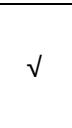 & $\sqrt{ }$ \\
\hline
\end{tabular}

The design of cultural tourism brand is composed by auditory factors, visual factors, factors of psychological perception and factors of comprehensive perception. These four factors constitute a complete image system of cultural tourism brand. (Zhang \& Wang, 2011) How does Mysterious Xiangxi construct and spread brand of "Mystery"? How do the four factors of cultural tourism brand design work together? The following parts will analyze the constructing strategies of "Mystery" from dimensions of representation meaning, interactive meaning and composition meaning respectively based on visual grammar and cooperative effect of the four factors.

\subsection{Representation meaning of "Mystery" in the Mysterious XiangXi}

In the introduction of Mysterious Xiangxi, the implication of mystery is represented by analytical processes of the conceptual representation. The nine scenes show the rugged mountains and green water, ancient city, Aizhai Bridge and so on. This part summarizes the features of mysterious Xiangxi--a peaceful utopia and a well-known ecological and cultural park at home and abroad. To further illustrate mysterious image, the publicity video is divided into four episodes. In the episode of "Green Xiangxi", it is to introduce unique natural environment of Xiangxi, its abundant green agricultural products and ecocultural tourism. There are thirty-five scenes in "Green Xiangxi" which can be divided into four parts. Part one presents Xiangxi's unique natural environment including primeval forests, Wetland park, You River and Wu River and so on (12 scenes). Part two introduces Xiangxi's ecological agriculture like by GuZhang Tea, BaoJing Golden Tea, kiwi fruit, Ponkan, JiuGui wine through action processes and reactional processes of narrative representation (six scenes). Part three informs the ecocultural tourism like MengDong River, QiFeng Lake, Dong River, Wetlands Park and so on through analytic processes of narrative representation. Part four describes the dynamics behaviors of tourists like running, climbing, drawing in the forest and so on to demonstrate that tourists indulge in the beautiful scenery by action processes of narrative meaning.

Analysis of "Green Xiangxi"

\begin{tabular}{|c|c|c|c|c|}
\hline $\begin{array}{c}\text { representatio } \\
\text { nal meaning }\end{array}$ & $\begin{array}{c}\text { analytical } \\
\text { process }\end{array}$ & $\begin{array}{c}\text { action } \\
\text { process and } \\
\text { reactional } \\
\text { process }\end{array}$ & $\begin{array}{c}\text { analytic } \\
\text { process }\end{array}$ & $\begin{array}{c}\text { action } \\
\text { process }\end{array}$ \\
\hline contents & $\begin{array}{c}\text { natural } \\
\text { environment }\end{array}$ & $\begin{array}{c}\text { ecological } \\
\text { agriculture }\end{array}$ & $\begin{array}{c}\text { eco- } \\
\text { cultural } \\
\text { tourism }\end{array}$ & $\begin{array}{c}\text { harmonious } \\
\text { coexistence } \\
\text { of human and } \\
\text { nature }\end{array}$ \\
\hline $\begin{array}{c}\text { distribution } \\
\text { of scene }\end{array}$ & 12 & 6 & 9 & 4 \\
\hline percentage & $41.9 \%$ & $19.3 \%$ & $29 \%$ & $12.9 \%$ \\
\hline
\end{tabular}

In "Cultural Xiangxi”, by action processes of narrative meaning, it introduces Xiangxi's long and mysterious history, culture of loving the family, loving the country and loving the world. By You River and Wu River which run through Xiangxi, it reviews the glorious history of the former great Qin Empire and Laosi Cheng. Then, by action processes of narrative meaning, it introduces the World Intangible Cultural Heritage, like Miao's Drum Dance, Miao Embroidery, Tujia Brocade, Laosi Cheng heritage site, the South Great Wall and so on. In addition, by action processes and reactional processes of narrative meaning, it is to convey humanistic spirit and folk culture vividly, making viewers experience personally feeling, like folk song of Miao, Maogusi dance of Tujia people, Chenhe High-pitched, Tujia Waving Dance and so on (18 scenes).

Analysis of "Cultural Xiangxi"

\begin{tabular}{|c|c|c|c|}
\hline $\begin{array}{c}\text { Representational } \\
\text { meaning }\end{array}$ & Action process & Action process & $\begin{array}{c}\text { Action process \& } \\
\text { reactional process }\end{array}$ \\
\hline Contents & $\begin{array}{c}\text { Great Qin } \\
\text { empire and } \\
\text { Laosi Cheng }\end{array}$ & $\begin{array}{c}\text { World } \\
\text { Intangible } \\
\text { Cultural } \\
\text { Heritage }\end{array}$ & $\begin{array}{c}\text { Humanistic spirit } \\
\text { and folk culture }\end{array}$ \\
\hline $\begin{array}{c}\text { Distribution } \\
\text { of scene }\end{array}$ & 16 & 12 & 27 \\
\hline Percentage & $29 \%$ & $21.8 \%$ & $49 \%$ \\
\hline
\end{tabular}

In "Open Xiangxi", on the one hand, it depicts the development of transportation in Xiangxi and establishment of the open platform; on the other hand, it displays the development of tourism and culture industry mainly by action processes of narrative meaning in order to attract investment and cooperation.

\section{Analysis of "Open Xiangxi"}

\begin{tabular}{|c|c|c|}
\hline $\begin{array}{c}\text { Representational } \\
\text { meaning }\end{array}$ & Action process & Action process \\
\hline Contents & $\begin{array}{c}\text { Transportation \& } \\
\text { tourism industry }\end{array}$ & $\begin{array}{c}\text { Combination of cultural } \\
\text { industry and tourism industry }\end{array}$ \\
\hline Distribution of scene & 16 & 50 \\
\hline Percentage & $24.2 \%$ & $75.8 \%$ \\
\hline
\end{tabular}


In "Harmonious Xiangxi", through action and reactional processes of narrative meaning, like smile, holding hands, toast, drinking, throwing caps and so on, these action and eye contact form the vectors, to expresses the harmony between Tujia and Miao minority and Han nationality, the harmony between tourists and local dwellers, reflecting Xiangxi's upward spiritual outlook. In addition, by the symbolic processes of the conceptual meaning, like light, lantern, fountain it indicates harmony and a better future for XiangXi.

\section{Analysis of "Harmonious Xiangxi"}

\begin{tabular}{|c|c|c|c|}
\hline $\begin{array}{c}\text { representational } \\
\text { meaning }\end{array}$ & $\begin{array}{c}\text { action } \\
\text { process }\end{array}$ & $\begin{array}{c}\text { reactional } \\
\text { process }\end{array}$ & $\begin{array}{c}\text { symbolic } \\
\text { process }\end{array}$ \\
\hline contents & $\begin{array}{c}\text { upward } \\
\text { spiritual } \\
\text { outlook }\end{array}$ & $\begin{array}{c}\text { harmony } \\
\text { between } \\
\text { tourists and } \\
\text { local dwellers }\end{array}$ & $\begin{array}{c}\text { light, lantern, } \\
\text { fountain }\end{array}$ \\
\hline $\begin{array}{c}\text { distribution of } \\
\text { scene }\end{array}$ & 26 & 8 & 3 \\
\hline percentage & $70.3 \%$ & $21.6 \%$ & $8.1 \%$ \\
\hline
\end{tabular}

In conclusion, the mysterious image of the publicity video Mysterious Xiangxi is mainly through action processes, reactional processes of narrative meaning and analytic processes of conceptual meaning. The mystery is mainly reflected by mysterious natural ecological environment and Nuo culture. Xiangxi's natural ecological environment is expressed by analytic processes of the conceptual meaning. It's mysterious humanistic spirit and folk culture is expressed by action processes and reactional processes of narrative meaning, making tourists experience the personal feelings. By the combination with movement and standstill, Mysterious Xiangxi weaves a delicate and mysterious scroll, compose a sweet and pleasant song and have a wonderful dream for the audience.

\subsection{Interactive meaning of "Mystery" in the Mysterious Xiangxi}

According to Kress \& van Leeuwen, if the viewer is not object, but subject of the look, and the represented participant is the object of the viewer's dispassionate scrutiny. No contact is made. This image is called "Offer". (Kress \& van Leeuwen, 2006 [1996]) In the video of 8'54" minutes, there was seldom eye contact between the participants and the viewers, except the girl in the Miao dress staring at viewers at $4{ }^{\prime} 15^{\prime \prime}$ minutes and people in the video waving to the audience viewers. Even in the reactional processes of the narrative meaning, the focuses of the eye contact are not the viewer because it intends to create a sense of mystery and charisma of Xiangxi. What's more, in the video, the cultural celebrities, like ShenCong wen, HunagYong yu, and SongZu ying, they don't have direct eye contact with the viewers, deliberately creating mysterious and profound culture of XiangXi. According to the different perspectives of the scene, distant lens and panoramic picture take more part in the video, in order to introduce the overall image of Xiangxi and pay attention to macro and integrity. From a global perspective, the social distance is set between image participants and viewers to highlight the mystery.
But in the introduction of specific intangible cultural heritage in XiangXi, like Miao items, Tujia brocade, Green agricultural products, close shots are used with the purpose to attract tourists and investors.

In order to take the viewer into the state of mysterious $X i a n g X i$ and experience local culture and maintain equal relationship between participants and viewers, the angle is frontal and eye level. But in the episode of "Cultural XiangXi", low angles are used to review the history of XiangXi, like the Qin Empire, TuSi system and show respects for the heroes and the depth of history because "low angles generally give an impression of superiority and triumph". (Kress \& van Leeuwen, 2006 [1996]) In terms of colour saturation, Mysterious Xiangxi has high modality and high color saturation. There are mainly distinctive colors like, red, blue and black of ethnic costumes and green Mountain and water in the video. On the contrary, in the retrospect of Qin dynasty between the $2^{\prime} 55^{\prime \prime}$ and $3^{\prime} 00^{\prime \prime}$, color saturation is low because it recreates the scene by performance. In addition, the video pays attention to contextualization, like snowflakes in the scene of monument, water waves in the scene of clear water, fog in the scene of green and mountain in order to present high modality.

To analyze the Mysterious Xiangxi from the contact of the interactive meaning, it is mainly "offer" rather than "demand". From the perspective of social distance, it uses long shot in order to keep distant and mysterious. In addition, the angle is frontal and eye level, it involves the viewers and brings them intuitive and authentic experiences and feelings. Finally, through saturation and details, it highlights the authenticity of Mysterious Xiangxi.

\subsection{Composition meaning of "Mystery" in the Mysterious Xiangxi}

In Mysterious Xiangxi, key information is distributed in the center, where the titles and the names of scenic spots are placed in this video. From the layout of words and images in the video of Mysterious Xiangxi, the words are on the left, which are the given information but the images are on the right, which are the new information. According to the analysis from the perspective of salience, images are in the foreground with large size and words are in the background with small size. From the perspective of color saturation, the natural environment is mainly presented by the green and grey color. The humanistic society is mainly expressed by the color of red, blue, yellow and black which make the cold and warm colors complement each other, enable to display a colorful and dynamic picture of mysterious and dynamic Xiangxi.

In conclusion, the brand image of "Mystery" is mainly represented from three dimensions of visual grammar. First, in representational meaning, "Mystery" in the video of Mysterious Xiangxi is mainly represented by action processes of narrative meaning and analytical processes of conceptual meaning to display the mysterious natural ecological environment, green ecological products and folk culture. Second, "Mystery" between the viewers and the participants is mainly formed through long shot, high 
modality and high color saturation. Third, "Mystery" is expressed by combination of information value, salience and framing, from the center to the margin, highlighting the core scenic spots like Aizhai Bridge and intangible cultural heritage like Tujia's Brocade in Xiangxi.

\section{Conclusion}

Based on the design of national culture tourism image, the publicity of Mysterious Xiangxi integrates factors of auditory, visual, psychological perception and comprehensive perception, paying special attention to visual elements and auditory elements, expressing the psychological perception factor through the folk festival culture, but there is still room for improvement in the presentation of comprehensive perception factors. For example, this video introduces the development of transportation and tourism industry, but it does not focus on the tourist service, transportation route, specialty food and local-style dwelling architectures.

According to the analysis of visual grammar and combining with four factors of cultural brand image design, this paper puts forward the following suggestions. First, optimize the representation of mysterious contents in Mysterious Xiangxi. It is suggested to increase and deepen the expression of the Nuo culture. It is necessary to precisely locate the mysterious culture in Xiangxi and find its core value and essence. The essence of the mysterious culture in Xiangxi is Nuo culture. It is necessary to further explore the creative design of Nuo culture, and reproduce the Nuo culture scientifically and innovatively while avoiding its sensitivity and feudalism. Second, strike the balance between the interaction and mystery with viewers. In the video of Mysterious Xiangxi, the interactive between the image and the viewer is limited. It is suggested to increase the interactive communication with the viewer because it can strengthen the psychological perception of tourists so as to better attract them. Third, strengthen the core elements of the mysterious brand. In addition to stressing the size and color of the core picture, the names of the core scenic spots can be highlighted to make the words and images more complementary.

In conclusion, to improve the communication validity of the mysterious brand image of Xiangxi, it is necessary not only to understand the cultural implication of the mysterious brand, but also to establish an effective multimodal discourse coordination mechanism

\section{Fund projects}

1. Hunan Philosophy and Social Science Fund Western Project, China (15YBX048): "Multi-dimensional discourse analysis and its countermeasures of publicity and tourism promotion Xiangxi in the global context"

2. National social science foundation of JiShou University, China (16SKA015): "Study on the strategies of external publicity and tourism promotion in WuLing mountain areas from multimodal perspective"

\section{References}

1. Li Baishan. On Creative Design of Witchcraft Culture and Remodeling the Mysterious Tourism of West Hunan [J]. Journal of HuaiHua University, 6, 45 (2012).

2. Hodge, Robert and Gunther Kress. Social Semiotics. Cambridge, UK: Polity Press in association with Basil Blackwell, Oxford, UK. (1988).

3. Kress, Gunther and Theo van Leeuwen. Reading Images: The Grammar of Visual Design (2 nd Edition). London: Routledge. [2006 (1996)].

4. Zhang Haiyan, Wang Zhongyun. Research of Establishing Ethnic Tourist Products Brand in Industrial Integration View [J]. Journal of Minzu University of China (Philosophy and Social Sciences Edition), 4,17-23(2011). 